\title{
Epidemiological and Clinical Characteristics of Confirmed Cases of Severe Fever With Thrombocytopenia Syndrome in Jeju Province, Korea, 2014-2018
}

\author{
Jinhee Kim ${ }^{1}$, Jong-Myon Bae ${ }^{1,2}$ \\ ${ }^{1}$ Jeju Center for Infectious Diseases Control and Prevention, Jeju, Korea; ${ }^{2}$ Department of Preventive Medicine, Jeju National University School of \\ Medicine, Jeju, Korea
}

Objectives: Jeju Province is well known as the region showing the highest incidence of severe fever with thrombocytopenia syndrome (SFTS) in South Korea. The aim of this study was to evaluate the epidemiological and clinical characteristics of SFTS patients in Jeju Province.

Methods: The primary data for this study were obtained from the Integrated Diseases and Health Control System of the Korea Centers for Disease Control and Prevention (KCDCIS). The selection criteria were confirmed cases of SFTS with a residence listed in Jeju Province at the time of diagnosis, reported to the KCDCIS between July 16, 2014 and November 30, 2018.

Results: Of 55 confirmed cases of SFTS, the case fatality rate was 10.9\% (95\% confidence interval [Cl], 4.1 to 22.2). The most common presenting symptoms at diagnosis of severe fever, myalgia, and diarrhea had incidences of $83.6 \%(95 \% \mathrm{Cl}, 71.2$ to 92.2$), 45.5 \%$ (95\% $\mathrm{Cl}, 32.0$ to 59.5$)$, and $40.0 \%(95 \% \mathrm{Cl}, 27.0$ to 54.1$)$, respectively.

Conclusions: Compared to SFTS patients nationwide in 2013-2015, the subjects of this study exhibited a lower case fatality rate and had a lower incidence of severe fever, myalgia, and confusion.

Key words: Tick-borne diseases, Thrombocytopenia, Diarrhea, Bunyaviridae infections

\section{INTRODUCTION}

Severe fever with thrombocytopenia syndrome (SFTS) is an infectious disease caused by a pathogenic virus known as SFTS bunyavirus (SFTSV), which is mediated through a vector, Haemaphysalis longicornis [1]. The disease was identified and named in March 2010 following observations made in central

Received: December 13, 2018 Accepted: April 2, 2019

Corresponding author: Jong-Myon Bae, MD, PhD

Department of Preventive Medicine, Jeju National University School of Medicine, 102 Jejudaehak-ro, Jeju 63243, Korea

E-mail: jmbae@jejunu.ac.kr

This is an Open Access article distributed under the terms of the Creative Commons Attribution Non-Commercial License (http://creativecommons.org/licenses/bync/4.0/) which permits unrestricted non-commercial use, distribution, and reproduction in any medium, provided the original work is properly cited.
China in 2009, where the infection manifested with major clinical symptoms of severe fever and thrombocytopenia [2].

A recent study by Bae et al. [3] argued that Korean SFTS patients presented with significantly more diarrhea and confusion compared to a group of Chinese patients studied previously, and this difference in the clinical presentation may have been associated with the difference in disease fatality rates between the 2 countries. Nevertheless, a limitation of the study by Bae et al. [3] was that they did not conduct a direct comparative analysis of the data from the 2 countries, but instead indirectly compared the statistical data extracted from the previously published literature $[4,5]$. Therefore, there is a need for a case-series study to determine whether patients diagnosed in Korea present more often with clinical symptoms of diarrhea and confusion. 
Jeju Province is recognized as a region with the highest incidence of SFTS relative to other areas of the country [5]. Thus, this research aims to study the epidemiological and clinical characteristics of the SFTS cases reported in Jeju residents after the disease became one of the communicable diseases required by law to report.

\section{METHODS}

Potential subjects of this study included confirmed cases of SFTS or suspected cases whose epidemiological characteristics were reported in the Integrated Diseases and Health Control System of the Korea Centers for Disease Control and Prevention (KCDCIS). The final selection criteria of the study were (1) patients who had their administrative addresses in Jeju Province, (2) incidents that occurred from the time of the first report (July 16, 2014) to November 30, 2018, and (3) patients with a diagnosis of SFTS who presented with corresponding clinical symptoms of the disease and met the diagnostic criteria for being confirmed as being infected with the pathogen.

The clinical symptoms of the disease can include severe fever $\left(38-40^{\circ} \mathrm{C}\right)$ lasting or 3-10 days; thrombocytopenia; leukopenia; gastrointestinal symptoms such as nausea, vomiting, and diarrhea; or swelling of lymph nodes 5 days after the initial onset of symptoms that lasts 1-2 weeks. Severe cases may present with multiorgan dysfunction, neurological disturbances, and confusion. Diagnostic criteria include isolation of viral particles from blood samples, identification of specific RNA from blood samples, and a 4-fold increase in serum antibody during the convalescent phase when compared to the acute phase of the disease.

General characteristics, clinical symptoms, and exposure factors were extracted from the registered epidemiological reports. From the general characteristics, occupations with high risk of exposure were categorized into agriculture, stockbreeding, forestry, construction, golf course management, and other occupations. Part-time employees who worked regularly in occupations with high exposure risks were also included in the appropriate occupational categories. For the clinical symptom criteria, severe fever was defined as a body temperature above $38^{\circ} \mathrm{C}$ according to the Korean Centers for Disease Control and Prevention's recommendations for tick-borne infectious diseases. General malaise and lethargy, which were categorized under 'other symptoms' in the original epidemiological report, were included in the category of 'fatigue'.
The $95 \%$ confidence intervals (Cls) of the case fatality rate and incidence of clinical symptoms were formulated using a normal distribution. As the test of independence, the Fisher exact test was used for $2 \times 2$ tables, and the chi-square test for the others. For statistical analysis, a statistical computing program, MedCalc version 18.11 (https://www.medcalc.org), was used. A $p$-value less than 0.05 was used as a cut-off for statistical significance. This study was deemed exempt from review by the Jeju National University Research Ethics Committee, as it utilizes secondary data that does not contain any personal information.

Table 1. Epidemiological characteristics of confirmed cases of severe fever with thrombocytopenia syndrome, Jeju Province, Korea, 2014-2018

\begin{tabular}{|c|c|c|c|c|}
\hline Characteristics & $\begin{array}{l}\text { Fatal } \\
(n=6)\end{array}$ & $\begin{array}{c}\text { Non-fatal } \\
(n=49)\end{array}$ & $\begin{array}{c}\text { Total } \\
(n=55)\end{array}$ & $p$-value ${ }^{1}$ \\
\hline Gender & & & & 0.66 \\
\hline Man & $4(66.7)$ & $28(57.1)$ & $32(58.2)$ & \\
\hline Women & 2 (33.3) & 21 (42.9) & $23(41.8)$ & \\
\hline Age (y) & & & & 0.34 \\
\hline$<40$ & $0(0.0)$ & $4(8.2)$ & $4(7.3)$ & \\
\hline $40-49$ & $0(0.0)$ & $7(14.3)$ & $7(12.7)$ & \\
\hline $50-59$ & $0(0.0)$ & $16(32.7)$ & $16(29.1)$ & \\
\hline $60-69$ & $4(66.7)$ & $11(22.4)$ & $15(27.3)$ & \\
\hline$\geq 70$ & 2 (33.3) & $11(22.4)$ & $13(23.6)$ & \\
\hline Residence & & & & 0.03 \\
\hline Jeju-si & $5(83.3)$ & $18(36.7)$ & $23(41.8)$ & \\
\hline Seogwipo-si & $1(16.7)$ & $31(63.3)$ & $32(58.2)$ & \\
\hline Diagnosis date & & & & 0.36 \\
\hline 2014 & $0(0.0)$ & $4(8.2)$ & $4(7.3)$ & \\
\hline 2015 & $0(0.0)$ & $9(18.4)$ & $9(16.4)$ & \\
\hline 2016 & $0(0.0)$ & 8 (16.3) & $8(14.5)$ & \\
\hline 2017 & $3(50.0)$ & $16(32.7)$ & 19 (34.5) & \\
\hline 2018 & $3(50.0)$ & $12(24.5)$ & $15(27.3)$ & \\
\hline Underlying disease ${ }^{2}$ & & & & 0.19 \\
\hline Yes & $3(50.0)$ & $37(75.5)$ & $40(72.7)$ & \\
\hline No & $3(50.0)$ & $12(24.5)$ & $15(27.3)$ & \\
\hline Occupation & & & & 0.25 \\
\hline Farm worker & $1(16.7)$ & $23(46.9)$ & $24(43.6)$ & \\
\hline Stockbreeder & $0(0.0)$ & $5(10.2)$ & $5(9.1)$ & \\
\hline Forest worker & $1(16.7)$ & $2(4.1)$ & $3(5.5)$ & \\
\hline Construction worker & $0(0.0)$ & $3(6.1)$ & $3(5.5)$ & \\
\hline Other & $4(66.7)$ & $16(32.7)$ & $20(36.4)$ & \\
\hline
\end{tabular}

Values are presented as number (\%).

${ }^{1}$ Fisher exact test for $2 \times 2$ tables; otherwise, chi-square test.

${ }^{2}$ Hypertension, diabetes mellitus, hepatitis B virus infection, tuberculosis, etc. 


\section{RESULTS}

From the period of the first reported case of SFTS in Jeju Province (July 16, 2014) to November 30, 2018, a total of 55 confirmed SFTS cases were reported, including 6 fatal cases, with a case fatality rate of $10.9 \%(95 \% \mathrm{Cl}, 4.1$ to 22.2$)$ (Table 1$)$. No fatalities were reported in patients under 60 years of age, and the number of fatal cases was significantly higher in patients diagnosed in Jeju-si than in those diagnosed in Seogwipo-si. However, no difference in fatality rates was noted with regard to gender, year of occurrence, occupation, or presence of underlying diseases.

As for the clinical characteristics, the incidences of the most common presenting symptoms, in order of decreasing occurrence, were severe fever, $83.6 \%(95 \% \mathrm{Cl}, 71.2$ to 92.2$)$; myalgia, $45.5 \%$ (95\% Cl, 32.0 to 59.5); and diarrhea, $40.0 \%$ (95\% Cl, 27.0 to 54.1) (Table 2). The incidence of confusion was relatively low, at 7.3\% (95\% Cl, 2.0 to 17.6). Laboratory analyses of blood samples were positive for leukopenia in $89.1 \%(95 \% \mathrm{Cl}, 77.8$ to 95.9) and for thrombocytopenia in $85.5 \%(95 \% \mathrm{Cl}, 73.7$ to 93.7) of cases. Despite myalgia being the only symptom exhibiting a statistically significant difference in incidence between fatal and non-fatal cases, it was the deceased patients who had no recorded complaints of myalgia.

\section{DISCUSSION}

To summarize our main findings, deaths among SFTS patients in Jeju Province occurred in the geriatric population over 60 years of age, with a $10.9 \%(95 \% \mathrm{Cl}, 4.1$ to 22.2$)$ case fatality rate, and the incidences of the most commonly clinical symptoms among all of the cases, in order of decreasing oc-

Table 2. Clinical manifestations of severe fever with thrombocytopenia syndrome in confirmed cases, Jeju Province, Korea, 20142018

\begin{tabular}{|c|c|c|c|c|c|c|}
\hline \multirow{2}{*}{ Categories } & \multirow{2}{*}{ Fatal $(n=6)$} & \multirow{2}{*}{ Non-fatal $(n=49)$} & \multirow{2}{*}{ Total $(n=55)$} & \multicolumn{2}{|c|}{$95 \%$ Cl of proportion } & \multirow{2}{*}{$p$-value ${ }^{1}$} \\
\hline & & & & LL & UL & \\
\hline Fever & $5(83.3)$ & $41(83.7)$ & 46 (83.6) & 71.2 & 92.2 & 0.98 \\
\hline Anorexia & $2(33.3)$ & $15(30.6)$ & $17(30.9)$ & 19.1 & 44.8 & 0.89 \\
\hline Myalgia & $0(0.0)$ & $25(51.0)$ & $25(45.5)$ & 32.0 & 59.5 & 0.02 \\
\hline \multicolumn{7}{|c|}{ Gastrointestinal symptoms } \\
\hline Nausea & $1(16.7)$ & $17(34.7)$ & $18(32.7)$ & 20.7 & 46.7 & 0.38 \\
\hline Vomiting & $1(16.7)$ & 8 (16.3) & $9(16.4)$ & 7.8 & 28.8 & 0.98 \\
\hline Diarrhea & $2(33.3)$ & $20(40.8)$ & $22(40.0)$ & 27.0 & 54.1 & 0.73 \\
\hline \multicolumn{7}{|c|}{ Nervous system symptoms } \\
\hline Mental deterioration & $1(16.7)$ & $3(6.1)$ & $4(7.3)$ & 2.0 & 17.6 & 0.35 \\
\hline \multicolumn{7}{|l|}{ Bleeding tendency } \\
\hline Melena & $0(0.0)$ & $2(4.1)$ & $2(3.6)$ & 0.4 & 12.5 & 0.62 \\
\hline Hematuria & $0(0.0)$ & $1(2.0)$ & $1(1.8)$ & 0.0 & 9.69 & 0.73 \\
\hline Hemorrhagia & $0(0.0)$ & $2(4.1)$ & $2(3.6)$ & 0.4 & 12.5 & 0.62 \\
\hline Others & $0(0.0)$ & $3(6.1)$ & $3(5.5)$ & 1.2 & 15.2 & 0.54 \\
\hline Enlarged-lymph nodes & $0(0.0)$ & $3(6.1)$ & $3(5.5)$ & 1.2 & 15.2 & 0.54 \\
\hline Other symptoms & $1(16.7)$ & 4 (8.2) & $5(9.1)$ & 3.0 & 20.0 & 0.50 \\
\hline
\end{tabular}

Cl, confidence interval; LL, lower limit; UL, upper limit.

${ }^{1}$ Fisher exact test. 
Table 3. Case fatality rates in reported references

\begin{tabular}{lcccc}
\hline & $\begin{array}{c}\text { China, } \\
\text { nationwide }\end{array}$ & $\begin{array}{c}\text { Korea, } \\
\text { nationwide }\end{array}$ & $\begin{array}{c}\text { Korea, } \\
\text { nationwide }\end{array}$ & $\begin{array}{c}\text { Korea, Jeju } \\
\text { Province }\end{array}$ \\
\hline $\begin{array}{l}\text { Incidence year } \\
2010-2013\end{array}$ & $2013-2015$ & $2014-2017$ & $2014-2018$ \\
$\begin{array}{l}\text { Case fatality } \\
\text { rate (\%) }\end{array}$ & 12.2 & 32.6 & 19.3 & 10.9 \\
\begin{tabular}{l} 
Source [Ref] \\
\hline
\end{tabular} & {$[4]$} & {$[5]$} & https://is.cdc.go.kr \\
\hline
\end{tabular}

currence, were severe fever (83.6\%), myalgia (45.5\%), and diarrhea (40.0\%).

The $10.9 \%$ case fatality rate of the SFTS patients diagnosed in Jeju Province between 2014 and 2018 was significantly lower than the $32.6 \%$ case fatality rate of Korean patients overall between 2013 and $2015(p<0.01)$ [5]. Actually, the case fatality rate of SFTS patients in Jeju Province was similar to the $12.2 \%$ ( $p=0.77$ ) case fatality of Chinese patients between 2010 and 2013 (Table 3) [4]. In order to improve the comparability of the current study, a nationwide data set from KCDCIS on the number of confirmed SFTS cases and the number of fatalities between 2014 and 2017 was analyzed. The analysis yielded a $19.3 \%$ ( $95 \% \mathrm{Cl}, 16.1$ to 22.8 ) case fatality rate, with 110 deaths from among a total of 571 patients. Two factors may be considered in discussing the recent trend toward reduced fatality. First, awareness of SFTS has recently increased among the general population as well as healthcare professionals, which could improve the prognosis at the time of diagnosis, and this could have influenced the recent decline in fatality. Second, taking into account the similar distribution of personal traits (gender and age group) among different studies, one must consider the potential difference in prognostic factors arising from treatments rendered after the diagnoses were made. However, because we were not able to obtain any information about the treatment procedures following the diagnoses, further comparative research is needed.

The $83.6 \%$ incidence of severe fever in patients from Jeju Province was significantly lower than those of China, $99.7 \%$, and South Korea (hereafter Korea) overall, $93.5 \%(p<0.01)$ [3]. The incidence of myalgia in Jeju patients, $45.5 \%$, was also significantly lower than those of China, $84.4 \%$, and Korea overall, $63.3 \%(p<0.01)$. Furthermore, the $7.3 \%$ incidence of confusion, a recognized prognostic factor of the disease, in Jeju patients was significantly lower than those of Korea overall, $25.6 \%$, and China, $21.1 \%$ ( $p=0.01$ ). In contrast, the $40.0 \%$ incidence of diarrhea in patients from Jeju Province was significantly lower than that of Korea, $54.3 \%(p=0.03)$, but showed no statistical difference from that of the Chinese patients,
$35.8 \%(p=0.52)$. To summarize, SFTS cases from Jeju exhibited a relatively low incidence of severe fever, myalgia, and confusion, and an incidence of diarrhea similar to the cases in China. This can be interpreted as showing that patients in Jeju Province between 2014 and 2018 presented with less severe symptoms compared to the patients in Korea overall between 2013 and 2015, which could have been associated with the lower rate of case fatalities when compared to the patients between 2013 and 2015.

Using the variables in Tables 1 and 2 that showed a statistically significant difference (age, address, myalgia) with regard to case fatality, an analysis of prognostic factors could have been performed. However, no such analysis was done in this study for 2 reasons. First, there was a possibility that the subjects' administrative addresses were different from their current addresses where the tick exposures were likely to have happened [6]. Second, none of the 6 deceased subjects were reported to have myalgia, which is a subjective clinical symptom that can only be elicited from the patients directly. Therefore, it was deemed inappropriate to evaluate the variables for potential prognostic factors based not on the medical records produced during treatment procedures, but on a database constructed from the notified report system. Two reasons would be a major limitation of this study.

In conclusion, the $10.9 \%(95 \% \mathrm{Cl}, 4.1$ to 22.2$)$ case fatality rate of SFTS patients in Jeju Province between 2014 and 2018 was lower than that of SFTS patients nationwide between 2013-2015, but it was closer to the $19.3 \%$ (95\% Cl, 16.1 to 22.8) fatality rate of SFTS patients nationwide during the similar observational period of 2014-2017 (Table 3). Interpretation of the above observation should take into account the fact that an enforced regional surveillance program has been implemented for infectious diseases, which enabled early detection and diagnosis of the patients. However, considering the official report from Jeju Province Department of Health that secondary SFTS infections had occurred in November of 2018 [7], there is still a need for health education for local residents on preventive measures for SFTS and for improved sharing of primary surveillance information among healthcare professionals who would be treating the patients.

\section{SUPPLEMENTAL MATERIALS}

Korean version is available at https://www.jpmph.org/. 


\section{CONFLICT OF INTEREST}

The authors have no conflicts of interest associated with the material presented in this paper.

\section{ORCID}

Jinhee Kim https://orcid.org/0000-0003-1629-9812

Jong-Myon Bae https://orcid.org/0000-0003-3080-7852

\section{REFERENCES}

1. Robles NJ, Han HJ, Park SJ, Choi YK. Epidemiology of severe fever and thrombocytopenia syndrome virus infection and the need for therapeutics for the prevention. Clin Exp Vaccine Res 2018;7(1):43-50.

2. Yu XJ, Liang MF, Zhang SY, Liu Y, Li JD, Sun YL, et al. Fever with thrombocytopenia associated with a novel bunyavirus in China. N Engl J Med 2011;364(16):1523-1532.
3. Bae JM. Differences of clinical manifestation of severe fever with thrombocytopenia syndrome between Korean and Chinese patients. J Korean Soc Emerg Med 2019;30(3) (in press).

4. Guo CT, Lu QB, Ding SJ, Hu CY, Hu JG, Wo Y, et al. Epidemiological and clinical characteristics of severe fever with thrombocytopenia syndrome (SFTS) in China: an integrated data analysis. Epidemiol Infect 2016;144(6):1345-1354.

5. Choi SJ, Park SW, Bae IG, Kim SH, Ryu SY, Kim HA, et al. Severe fever with thrombocytopenia syndrome in South Korea, 20132015. PLoS Negl Trop Dis 2016;10(12):e0005264.

6. Bae JM. Epidemiological characteristics of scrub typhus on the Jeju Island. Epidemiol Health 2017;39:e2017060.

7. Jeju Special Self-Governing Province. Report of second infection on severe fever and thrombocytopenia syndrome [cited 2018 Dec 13]. Available from: https://www.jeju.go.kr/news/ bodo/list.htm;jsessionid = GJjkn12worQo605EqLshkscdkgCO 570pLYkeOpjw3K9Yiql80kfrH8yT2dBCCDaz.was2_servlet_ engine6? category $=84 \& \_$layout $=$playout $\& \_v i e w=$ print $\&$ pag $\mathrm{e}=3 \&$ act $=$ view\&seq $=1120332$ (Korean). 